\title{
Factors affecting the utilisation of electronic medical records system in Malawian central hospitals
}

\author{
Khwima E. Mkalira Msiska ${ }^{1}$, Andrew Kumitawa ${ }^{1}$, Benjamin Kumwenda ${ }^{2}$ \\ 1. Department of Public Health, College of Medicine, University of Malawi, Blantyre, Malawi \\ 2. Department of Biomedical Sciences, College of Medicine, University of Malawi, Blantyre, Malawi
}

\section{Background}

In Malawi, paper-based medical record-keeping has been observed to exacerbate challenges related to accessing patient records and patient tracking. Despite the introduction of electronic medical record (EMR) systems in 2001, paper-based records continue to be in use. Some health workers prefer paper-based records to EMRs. This study assessed factors that affect the use of EMRs in Malawi, particularly at Queen Elizabeth and Kamuzu Central Hospitals. It further investigated the reasons why paper-based records are still in use despite the numerous associated disadvantages. The extent to which EMRs contribute to patient care was also analysed.

Methods

In this cross-sectional study, 111 randomly selected health workers were interviewed, using a semistructured questionnaire, at the 2 largest central hospitals in Malawi, where EMRs were first introduced in the country. Focus group discussions were conducted to gather further information on factors identified during the individual interviews.

Results and conclusions

Differences in age, gender, and previous computer experience were not associated with differences in EMR usage. However, education and employment levels has a positive association with EMR usage. Hardware and connectivity problems, as well as lack of training and managerial support negatively affected the use of EMRs. EMRs were found to improve data quality and efficiency in patient management.

\section{Introduction}

The use of information technology (IT) in health has revolutionised and improved the delivery of healthcare services globally. IT has been applied in hospitals for the administration and management of patients, human resources, procurement, emergency fleet management, and much more. Previously, all such tasks were managed using paper-based record-keeping systems, which proved to be inefficient in terms of information retrieval, security, and data quality and also did not allow concurrent data access.

Paper-based records are still used by health workers largely because many healthcare workers are more familiar with paper-based records after long-term use. ${ }^{1}$ Paper-based recordkeeping does not require the relatively high level of technical knowledge and skills needed for electronic record-keeping. Paper-based record systems can be used by people with less education or, indeed, with no training at all. ${ }^{1}$ However, paper-based records have a number of limitations. Illegible handwriting makes it difficult for others to read, which can result in errors and consequently compromise the quality of data captured. Poor data quality has serious implications on patient care, such as mixing of laboratory samples and provision of incorrect drug prescriptions. Paper-based record systems lack confidentiality because they are shared among many users and patient privacy can be easily compromised. ${ }^{2}$ Unauthorised users can easily access information as it gets transferred from one point to another. Patient follow-up is also difficult in paper-based record systems, which in turn disrupts continuity of care. ${ }^{3}$ Electronic medical records provide a solution to the limitations of paper-based systems. The past decade has seen a rapid increase in the use of IT in both developed and developing countries. ${ }^{4-5}$ In Malawi, patient records were for a long time managed using a paperbased system until 2001, ${ }^{6}$ when a computerised patient management information system was introduced. Since then, electronic medical records (EMRs) systems have transformed the delivery of healthcare services. ${ }^{7-8}$

An EMR is an individual's health-related information record, which is recorded using computer software. It is generated, collected, managed, and used by authorised healthcare workers within a healthcare institution. ${ }^{9}$ Electronic records provide substantial benefits to healthcare workers and organisations in patient management and are quickly replacing paper-based records, which have been used for centuries in health systems. ${ }^{10}$ EMR systems solve many of the limitations of paper-based systems. EMR systems have proved to be efficient and cost-effective in improving the quality of health services. EMR systems improve accessibility to health records, as well as the quality and accuracy of patient information. ${ }^{5,11}$ In view of these benefits of EMRs, healthcare providers have widely adopted EMR use in healthcare globally. ${ }^{12,13}$

EMRs have been found to improve the quality of patient care, as they enable storage of large amounts of data and also facilitate quick data retrieval, which reduces time pressure on health workers. ${ }^{11}$ EMRs require less data storage space and minimise the loss of patient records. ${ }^{5-11}$ However, EMR systems still have their challenges, including lack of computer skills among health workers, frequent computer breakdowns, power failures, negative attitudes of health workers towards EMR systems, and the costs of staff training on such systems. ${ }^{3}$

EMRs were first introduced into the Malawian public health system at Kamuzu Central Hospital (KCH) in Lilongwe in 
2001 by the Baobab Health Project (BHP) in conjunction with the Ministry of Health $(\mathrm{MOH}) \cdot{ }^{10-15} \mathrm{KCH}$ is situated in the capital city, Lilongwe, in Malawi's Central Region, and it is the second largest public referral hospital in the country, after Queen Elizabeth Central Hospital (QECH) in the Southern Region. KCH mainly provides specialised services and it serves as a referral for the entire central region.

In 2005, the EMR system was extended to QECH in Blantyre. ${ }^{10-14} \mathrm{QECH}$ is the largest government referral hospital in country; it provides primary, secondary, and tertiary healthcare services for the Southern Region and other specialised services for the whole country. It also serves as a teaching and research hospital for the College of Medicine, a constituent college of the University of Malawi, and its research affiliates. ${ }^{16}$ Despite the introduction of EMRs in Malawi, a considerable proportion of healthcare workers are still using paper-based records. ${ }^{6}$ It is not clear why hospital management teams have not enforced a complete transition from paper-based records to EMRs.

Several studies have investigated the use of EMRs both locally and internationally. A survey conducted at the QECH Antiretroviral Therapy (ART) Clinic found that $70 \%$ of respondents preferred using the EMR system over paperbased records. ${ }^{10}$ However, users identified several problems with the use of the EMR system; these included inadequate computer skills and unreliable computer network connectivity. SanJoaquin et al., ${ }^{3}$ identified several EMR-related challenges, including frequent power failure. However, the problem of prolonged power outages was addressed by the adoption of a long-lasting backup power system in conjunction with energy-efficient computers. Although there have been several studies conducted at QECH and $\mathrm{KCH}$ focusing on EMRs, these studies concentrated on specific departments rather than the entire hospital. As such, these studies were not representative enough to draw conclusions on the general performance of EMR systems in central hospitals. This study therefore attempted to comprehensively study factors that affect the utilisation of EMRs in Malawi. The study investigated existing factors uncovered in prior studies, but also attempted to uncover new factors specific to Malawi, particularly at $\mathrm{KCH}$ and $\mathrm{QECH}$, which might have emerged after using EMRs for some time. The objectives of the study were to (1) assess knowledge and attitudes of health workers towards the use of EMRs; (2) identify technical, infrastructural, and managerial factors that affect the utilisation of EMR systems; and (3) investigate how EMR usage affects the delivery of health services.

\section{Methods}

The study was conducted at Queen Elizabeth and Kamuzu Central Hospitals. These hospitals are the 2 largest referral hospitals in Malawi in terms of bed capacity and specialised services offered. They also have been running EMRs for a longer period of time than any other hospital in the country, which allowed for sufficient information and experiences for investigation in this study. Data collected from the 2 hospitals provided a true reflection on the status of EMR usage in Malawi.

This was a cross-sectional study which applied both quantitative and qualitative techniques. The study population included health workers, from various departments, who were using EMRs, as well as those who had stopped using electronic records. Health workers investigated in this study included data clerks, nurses, clinicians, laboratory technicians, and HIV counsellors.
Table 1: Respondent characteristics

\begin{tabular}{lccc}
\hline Characteristic & QECH & KCH & Total \\
\hline Gender & & & \\
Male & $40(74.1 \%)$ & $14(25.9 \%)$ & 54 \\
Female & $46(80.7 \%)$ & $11(19.3 \%)$ & 57 \\
Job title & & & \\
Data clerk & $26(68.4 \%)$ & $12(31.6 \%)$ & 38 \\
Nurse & $30(69.8 \%)$ & $13(30.2 \%)$ & 43 \\
Clinician & $27(100 \%)$ & 0 & 27 \\
Laboratory technician & $2(100 \%)$ & 0 & 2 \\
HIV counsellor & $1(100 \%)$ & 0 & 1 \\
Level of education & & & \\
Secondary & $15(62.5 \%)$ & $9(37.5 \%)$ & 24 \\
Tertiary & $71(81.6 \%)$ & $16(18.4 \%)$ & 87 \\
\hline
\end{tabular}

$\mathrm{QECH}=$ Queen Elizabeth Central Hospital (Blantyre); KCH = Kamuzu Central Hospital (KCH)

At QECH there were 5 departments that used EMRs, with a total of 139 health workers. The 5 departments were the Department of Medicine, ART Clinic, the Department of Paediatrics, the Adult Emergency and Trauma Centre (AETC), and the Laboratory Department. Only the medical, outpatient, and maternity (Ethel Mutharika Maternity Wing) departments were using EMRs at $\mathrm{KCH}$, with a total of 40 health workers. The 111 participants included in this study were randomly sampled from the 179 workers in the study population. A semistructured questionnaire was used to collect data. The questionnaire comprised sections such as demographics; positive and negative factors affecting EMR usage; previous computer knowledge and training; general attitude towards EMR; and technological, managerial and infrastructural factors affecting EMR use. This method was guided by the Performance of Routine Information System Management (PRISM) framework, which identifies technical, behavioural, and organisational factors that affect routine collection of health information such as using EMR. ${ }^{21}(21)$

Data were analysed using Stata version 12 (StataCorp, College Station, TX, USA). Sociodemographic variables (gender, educational level, job title) were summarised using frequencies and proportions. The use of EMR system functions, computing experience, usage frequency, and attitude towards EMRs were analysed using mean sum scores. Mean sum scores were also calculated for technical, managerial, and infrastructural factors. Chi-square analysis was used to assess associations among variables such as age, gender, educational level, job title and previous computing experience. In order to determine how EMR usage affected the delivery of health services, proportions were calculated on completeness, accuracy, and security of the information. Time taken to attend to patients and ease of use were also analysed.

\section{Ethical considerations}

Participation in the study was voluntary. Participants were free to discontinue responding to the questionnaire or interview at any time. Verbal explanations about the study were made privately before obtaining written consent from each participant. Information collected in the study was kept strictly confidential, concealed, and it was used strictly for the purposes of this study. There were no known risks for participating in the study. There were no incentives provided 


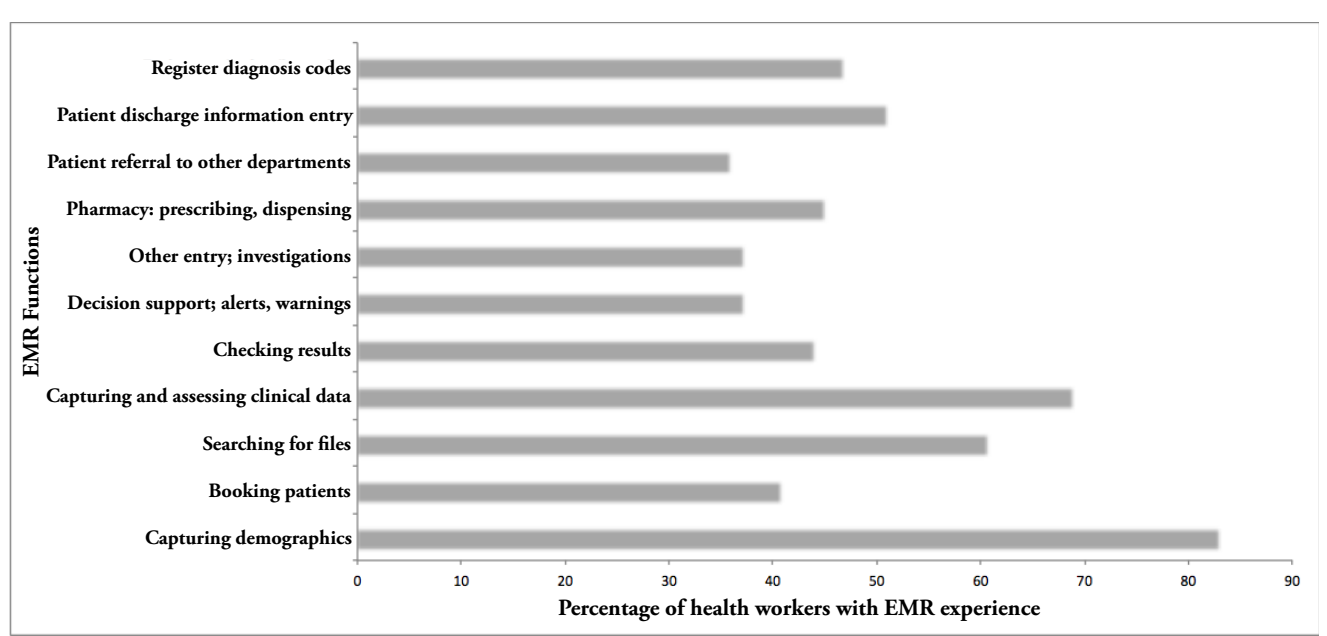

Figure 1: Use of electronic medical record functions at Queen Elizabeth Central Hospital (Blantyre) and Kamuzu Central Hospital (Lilongwe)

for participating in the study. However, the intended positive contribution of the study to the health system in Malawi was explained to participants. The study was reviewed and approved by the College of Medicine Research and Ethics Committee (COMREC).

\section{Results and discussion}

EMR use among study participants varied with demographic characteristics; EMR knowledge; previous computer experience; frequency in usage of EMR; attitudes towards EMRs; and technological, managerial, and infrastructural factors.

\section{Study participants}

There were a total of 111 participants interviewed in this study who were collectively sampled from QECH and $\mathrm{KCH}$. Since QECH had more departments than $\mathrm{KCH}$ that used EMRs, it had more participants sampled ( $\mathrm{n}=86 / 111 ; 77.5 \%)$. In terms of profession, nurses ( $n=43 / 111 ; 38.7 \%$ ) made up the largest proportion of study participants, followed by data clerks $(\mathrm{n}=38 ; 34.2 \%)$ and clinicians $(\mathrm{n}=27 ; 24.3 \%)$. The total number of participants varied from question to question since some participants did not respond to all the questions. Table 1 shows the frequency distributions of gender, job title, and education levels among study participants.

\section{Utilisation of EMR functions}

Frequently used EMR functions were investigated to determine usage behaviour and possible technological correlates in the system design. Both human and technical determinants, as guided by the PRISM framework, were analysed.

Utilisation of EMR functions varied among departments as well as among users. Health workers used half of the system functions shown in Figure 1 for different reasons. The most commonly used functions were capturing demographics ( $\mathrm{n}=$ $92 / 111 ; 82.9 \%$ ), followed by capturing and assessing clinical data $(\mathrm{n}=75 / 109 ; 68.8 \%)$. These functions were frequently used because they applied to almost all patients who visited the hospital. More efforts need to be applied to these functions, as they have a substantial influence on perceptions of the entire EMR system. These results are similar to those reported by Nour El Din ${ }^{17}$ in Saudi Arabia, wherein 48\% of the core EMR functions were not utilised by physicians because they were unaware of their availability in the system. The authors also found that the freedom that system users had to choose between EMRs and paper-based records led to low usage of some of the EMR functions.

\section{EMR training}

EMR training instills confidence in the usage of the EMRs among users. ${ }^{18-19}$ There were 76 respondents (72.4\% of 105 for whom data were available for analysis) who had received basic training on EMR use. Few respondents $(\mathrm{n}=8 / 105$; $7.6 \%$ received advanced training. Many respondents ( $\mathrm{n}=21 / 105 ; 20.0 \%$ ) claimed not to have received any training at all. Clerks showed better understanding and knowledge of the EMRs compared to all other workers. This was probably because clerks used the system more frequently than the other staff workers. At the $\mathrm{KCH}$ medical department, data were captured only during day shifts but not at night. This was because most night shift healthcare staff worked part-time and were not trained to use the EMR system. Training plays a major role in promoting effective utilisation of EMRs. ${ }^{20}$

\section{Attitudes towards EMR usage}

Most respondents ( $\mathrm{n}=79 / 107 ; 73.8 \%$ ) indicated that EMR use did not interfere with serving patients during consultations. Additionally, $72(65.5 \%)$ of 110 participants responded that computers were equally beneficial for both administrative and clinical functions. A large proportion of respondents ( $\mathrm{n}=77 / 110 ; 70.0 \%$ ) strongly felt that EMRs were more useful than paper-based systems. Overall, health workers had positive attitudes towards the use of EMRs, as compared to paper-based records.

\section{Technological factors affecting EMR utilisation}

Of the technological factors that were analysed (system information, terminologies used, screen design and layout, system capabilities, and availability of technical support), system features had the lowest mean score (2.5). Screen design and layout had the highest mean score (3.0). Even if a system is useful and has all the necessary functions, poor design could deter users from using the system. Human-computer interaction factors, such as system features, colour, attractiveness, and usability of the system heavily affect system usage. The PRISM framework identifies technical determinants as one of the major factors that affect performance of routine collection of health information. ${ }^{21}$

A high proportion of the participants favoured the technological characteristics of the EMR system, with $82(75.9 \%)$ of 108 respondents agreeing that EMRs are beneficial because they are easier and faster to use than paperbased systems. Seventy-seven (70.6\%) of 109 respondents also agreed that the EMR system terminologies were related to the performed task. EMR systems currently function well for data entry and reporting and a large number of users are involved in these tasks. It is therefore not surprising $70.6 \%$ of respondents found EMR terminology applicable to their tasks. The system provided information that users needed for their tasks, and they found that the screen features were 


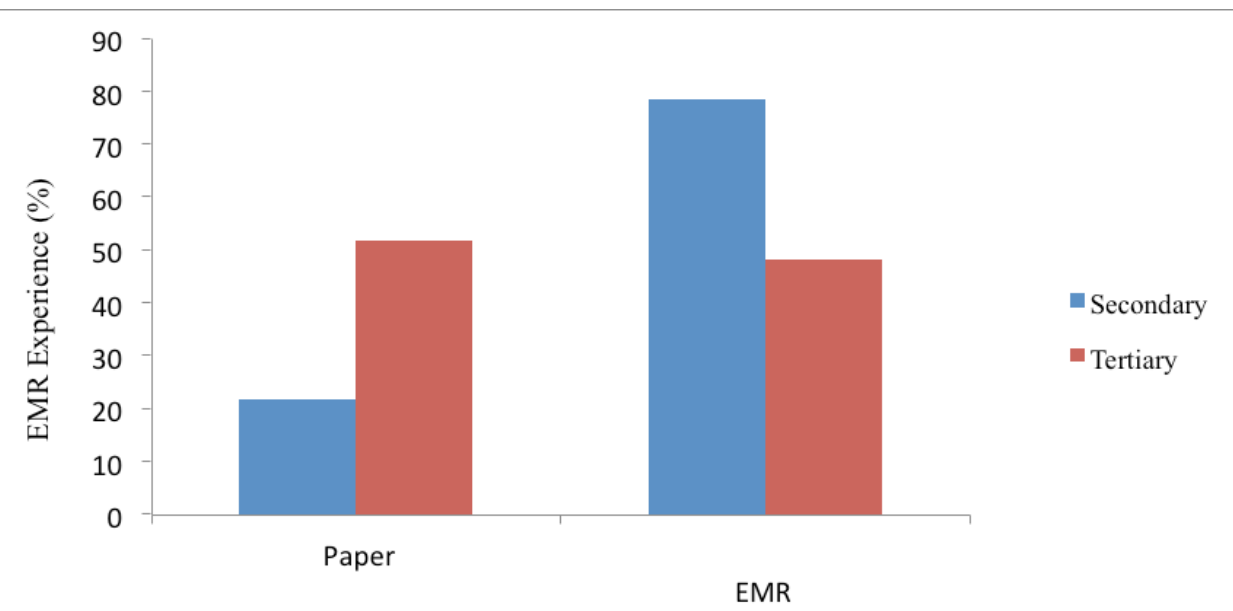

Figure 2: Education level and electronic medical record utilisation among health workers

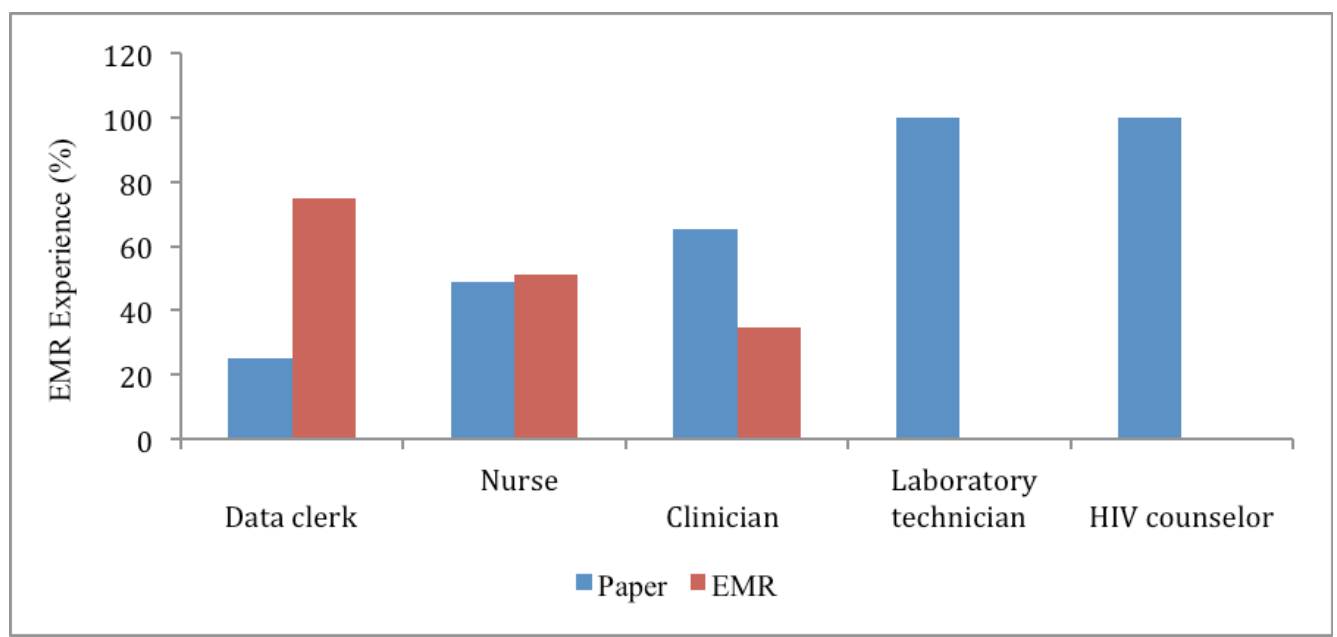

Figure 3: Electronic medical record usage versus paper-based records usage by job title

logically organised. This indicated that the system promoted quality health service delivery, which eventually improves healthcare services. Participants suggested that the system could be more effective if it was enforced and implemented in all departments. Participants suggested that the system could be more effective if it was enforced and implemented in all departments. It was unfortunate that some departments had stopped using EMRs because they claimed that the system failed to capture adequate patient information that clinicians needed for patient management. This finding is similar to what Msukwa ${ }^{22}$ reported-that $22 \%$ of clinicians were not satisfied with EMRs because the information collected in the EMR system was judged to be inaccurate and incomplete. Similarly, Alharthi ${ }^{23}$ found that physicians were not happy with the accuracy and completeness of records captured in EMR systems.

\section{Managerial and infrastructural factors}

Availability of resources and managerial support were analysed to determine their effects on EMR use. Even in the context of high-quality EMR systems, a lack of managerial support can lead to divergent priorities in resource allocation and hinder the success of EMR implementation. Seventy-eight (73.6\%) out of 106 participants agreed that the EMR system was important to hospital managers. There was disagreement among respondents about whether or not management supported the use of the EMR system. Half of respondents ( $\mathrm{n}=52 / 104)$ agreed that management provided support and resources for EMR use, with a category mean score of 2.7 (standard deviation [SD] $=0.94 ; \quad(95 \%$ confidence interval $[\mathrm{CI}]=2.56$ to 2.92). The remaining half indicated that management did not provide support and resources for EMR use. Managers lacked adequate knowledge on the benefits of EMR use by supervisors, as evidenced by the lack of enforcement on EMR use and absence of explicit EMR policies at both hospitals.

Availability of space for EMR machinery and convenience of location were among the infrastructural factors investigated. Most respondents ( $\mathrm{n}=$ $93 / 107 ; 86.9 \%$ ) found that the spaces where EMR computers were mounted were convenient to use. The category mean score was $3.1(95 \% \mathrm{CI}=2.93$ to 3.25$)$. It was only in the medical department at QECH where respondents complained that computers were placed inconveniently-too close to patients' beds, which made access to the EMR computers difficult and compromised the privacy and security of patients' data. In such circumstances, paperbased records were preferred over EMRs. At the $\mathrm{KCH}$ medical department and the QECH paediatrics department, there were not enough computers, which made EMR usage difficult. Ayotallahi ${ }^{24}$ and Lium ${ }^{25}$ also found that computer availability was one of the major factors that affected EMR use; having inadequate or too few computers and mounting them in inconvenient locations due to lack of space negatively affected the utilisation of EMR systems, particularly, among physicians.

\section{Association of age, gender, job title, educational levels, and previous computing experience with EMR utilisation}

Thirty-four (58.6\%) of 58 respondents within the 21 - to 30year age group used EMRs more than paper-based records. This study only included 2 participants aged 61 to 70 years and both used paper more than electronic records. Despite this variation, the differences in EMR versus paper-based record usage were not statistically significant among age groups $(\mathrm{P}=0.93)$. These findings are consistent with those reported in a study by Nour El Din ${ }^{17}$ who found that health worker age was not associated with EMR versus paper record use preferences. However, these findings contradicted results from several prior studies that found that younger health workers used EMRs more than older health workers. ${ }^{19,24,26}$ 


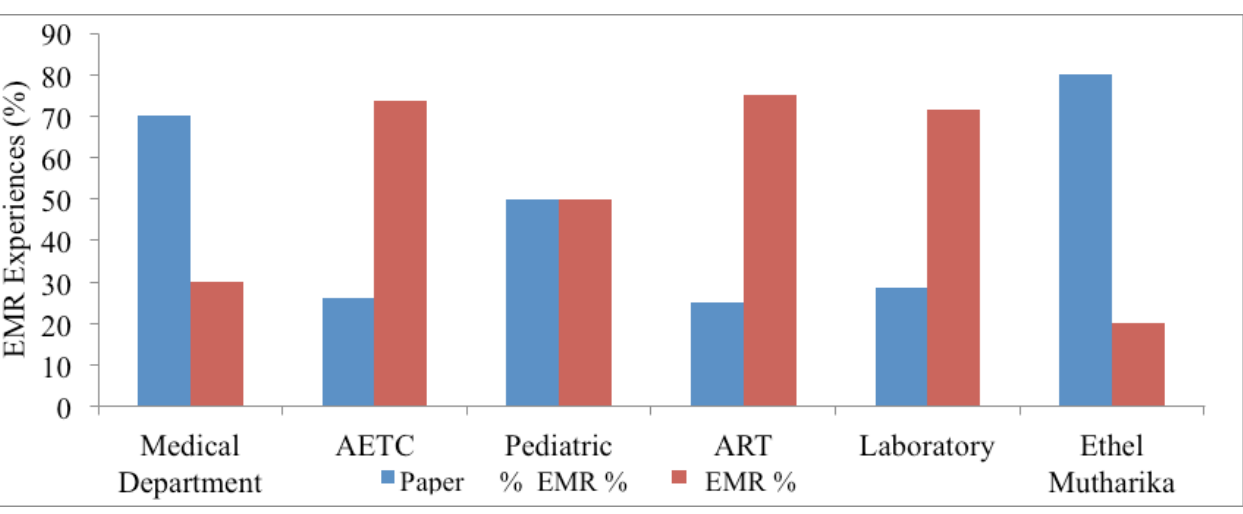

Figure 4: Electronic medical record usage versus paper-based records usage by department

Table 2: Previous computer experience and use of electronic medical records (EMRs) among health workers

\begin{tabular}{lcccccc}
\hline Variable & Paper-based & EMR & Total & Chi-square & df & P-value \\
\hline Previous computer usage & $37(46.3 \%)$ & $43(53.8 \%)$ & 80 & & & \\
No previous computer usage & $12(44.4 \%)$ & $15(55.6 \%)$ & 27 & & 1 & 0.89 \\
\hline Total & $\mathbf{4 9 ( 4 5 . 8 \% )}$ & $\mathbf{5 8 ( 5 4 . 2 \% )}$ & $\mathbf{1 0 7}$ & & & \\
\hline
\end{tabular}

There was no significant difference between males and females in terms of EMR versus paper-based record preference $(\mathrm{P}=$ 0.35). This was probably because males and females have equal exposure to technology in modern contexts. These findings are consistent with a study that was conducted in Kenya on the usage of electronic medical records among healthcare workers in selected health facilities, where gender did not affect EMR use. ${ }^{27}$

EMR usage varied significantly by educational level among the study participants $(\mathrm{P}=0.01)$. Health workers with tertiary-level education used EMRs and paper-based records in nearly equal proportions. However those with secondarylevel education used EMRs more than paper-based records (Figure 2).

This was possibly because most health workers with secondary education were clerks and their scope of EMR usage was mostly limited to the single EMR function of collecting patient demographic information. In addition, clerks were regularly supervised, and they were mandated to perform their tasks by their supervisors. In contrast, a study conducted in Kenya on the use of EMRs among healthcare workers in selected health facilities found no association between educational levels and EMR usage habits. ${ }^{27}$

Figure 3 depicts the association between job title and EMR usage. Most data clerks ( $\mathrm{n}=27 / 36 ; 75.0 \%$ ) used EMRs more often than paper-based records. Nearly two-thirds of the clinician respondents $(n=17 / 26 ; 65.4 \%)$ preferred using paper-based records more than EMRs. According to job title, the variation in preference for either EMR or paper record usage among the participants was not statistically significant $(\mathrm{P}=0.07)$.

Figure 4 shows usage comparisons between EMRs and paperbased records according to participating departments. AETC (which functioned as both an emergency and outpatient department at QECH at the time of data collection), the QECH ART Clinic, and the QECH laboratory used EMRs more frequently than they did paper records. The medical departments in the participating hospitals and the Ethel
Mutharika Maternity Wing at $\mathrm{KCH}$ used paper-based records more often than EMRs. The paediatric departments used paperbased records at the same frequency as EMRs. Overall (in all departments put together), EMRs were used more frequently than paper-based records, and this difference was statistically significant $(\mathrm{P}=$ 0.01). Higher EMR usage in AETC might have arisen because this is the first point of initial contact for most patients in the hospital, and where their details are first captured in the system. Lack of supervision in the medical departments and the inconvenient locations of the EMR computers may have contributed to low EMR uptake in the medical wards. Additionally, much of the record keeping in the medical wards is carried out by clinicians, and as shown earlier (Figure 3), clinicians were more inclined to use paper records.

Comparing usage between hospitals, health workers at QECH (61.9\%) used EMRs more frequently than at $\mathrm{KCH}$ $(25 \%)$. This difference was statistically significant $(\mathrm{P}=0.03)$. The focus group discussions revealed that lack of managerial support resulting from frequent leadership changes, lack of EMR training, and low staff retention contributed to low EMR usage at $\mathrm{KCH}$.

Most of the participants $(75 \%)$ had some experience using computers. There was no statistically significant difference in EMR usage between individuals with and without previous computing experience $(\mathrm{P}=0.89$ ) (Table 2$)$. In contrast to these findings, Laerum et al. ${ }^{28}$ found that computer illiteracy contributed to limited EMR among health workers. Similarly, Meinert and Peterson ${ }^{29}$ observed that limited computer literacy on the part of physicians contributed to resistance to EMR use. Most users in this study were not familiar with the touchscreen computers, which probably acted to somewhat cancel out their overall computing experience differences.

\section{Effect of EMRs on the delivery of health services}

The majority of respondents ( $\mathrm{n}=78 / 103$; 676\%) found EMRs to be faster and easier to use than paper-based records. Most respondents $(84 / 108,77.8 \%)$ felt that information was more accurate in the EMR system and that patients were attended to more quickly than with the paper-based records system. Eighty-three of 108 respondents (76.9\%) indicated that the EMRs maintained privacy and security of patient information. Participants stated that EMRs enabled health workers to generate more accurate information, speed up access to patient information, and they expressed satisfaction with the reminders and warnings about important patient and prescription information. This reduced medical errors and improved decision-making for patient management. The use of EMRs also enabled clinicians to assess more patients 
within a shorter period of time. Giaedi ${ }^{30}$ found that the use of EMR systems reduced access time to patient records; EMRs also reduced costs related to paper consumption. EMR utilisation also reduced the pressure on the already limited number of health staff, as less time was spent retrieving records thereby freeing more time for patient management. Moreover, EMR usage increased patients' satisfaction because patients were given quick, thorough and adequate information. ${ }^{30}$

\section{Conclusions}

This study investigated factors that affect the utilisation of EMR systems by health workers in Malawi particularly, at central hospitals. There was higher usage of EMRs at QECH compared to $\mathrm{KCH}$, even though EMRs were first introduced at $\mathrm{KCH}$. Short supplies of computers and inconvenient locations of EMR machines heavily affected EMR usage in some departments. Health workers still found EMRs to be quicker, more secure, and more accurate in aiding patient management compared to paper-based records. Electronic record-keeping enabled clinicians to consult more patients within a short period of time compared to paper records. EMRs also reduced healthcare staff workload, as less time was spent retrieving paper records. Age, gender, and previous computer experience had no effect on EMR usage frequency. However, the lack of EMR training and managerial support were among factors that negatively affected EMR uptake by healthcare workers. Educational level was also found to significantly influence EMR utilisation.

The overall attitude of health workers towards EMR usage was positive. The findings from this study may guide hospital management, system designers, installers, users and nonusers on measures for improving the use of the EMRs to improve health service delivery. Future research will be required to address patient attitudes towards EMRs in this context and to address patients' concerns related to the use of EMR systems in Malawi.

\section{Acknowledgements}

We would like to thank study participants at Queen Elizabeth and Kamuzu Central Hospitals for their willingness to take time out of their busy schedules to participate in this study. We also thank the David Livingstone Bicentenary Scholarship Programme for the financial support towards this project.

\section{Competing interests}

All authors declare that they have no competing interests related to this work.

\section{References}

1. Fitzpatrick, G. Understanding the Paper Health Record in Practice: Implications for EHRs [online]. In: Pradhan, Malcom (Editor); HIC 2000: Proceedings. Brunswick, Vic.: Health Informatics Society of Australia, 2000: [323-331]. [Accessed 21 Jan 17]. Availability: <http:// search.informit.com.au/documentSummary; $\mathrm{dn}=923212919867674$;res $=$ IELHEA > ISBN: 0958537054

2. Job O, Bachmann LM, Schmid MK, Thiel MA, Ivic S. Assessing the efficacy of the electronic patient record system EDeR: implementation study--study protocol. BMJ Open [Internet]. 2013 [Accessed 20 August 2015]; 3(4):1-5. Available from: http://www.pubmedcentral.nih.gov/ articlerender.fogi? artid $=3641441 \&$ tool $=$ pmcentre $\&$ rendertype $=$ abstra ct.

3. SanJoaquin MA, Allain TJ, Molyneux ME, Benjamin L et al. PLOS Medicine Surveillance Programme of IN-patients and Epidemiology (SPINE) Implementation of an Electronic Data Collection Tool within a Large Hospital in Malawi. PLoS Med. 2013;10(3).
4. Sood SP, Nwabueze SN, Mbarika VWA, Prakash N, Chatterjes S, Ray P, et al. Electronic Medical Records : A Review Comparing the Challenges in Developed and Developing Countries. Proceedings of the st Hawaii International Conference on System Sciences. 2008. p. 1-10.

5. Humpage SD. Records : Benefits and Costs of Electronic Medical Records : The experience of Mexico's Social Security Institute. 2010. [Accessed 30 August 2017] Available from: https://publications.iadb. org/

6. Douglas GP, Gadabu OJ, Joukes S, Mumba S, McKay MV, BenSmith A, Jahn A, Schouten EJ, Lewis LZ, van Oosterhout JJ, Allain TJ, Zachariah R, Berger SD, Harries AD CF. PLOS Medicine Using Touchscreen Electronic Medical Record Systems to Support and Monitor National Scale-Up of Antiretroviral Therapy in Malawi. PLoS Med. 2010;7(8).

7. WHO. Management of Patient Information Trends and Challenges in Member States. Global Observatory for eHealth series. 2012; (6).

8. Chetley A. Improving health, Connecting People: the role of ICTs in the Health Sector of Developing Countries: A Framework Paper [Internet]. Working Paper NO 1; 2006 [Accessed 20 June 2013]. Available from: http://www.infobridge.org/asp/documents/3254.pdf.

9. Electronic Medical Record Systems _ AHRQ National Resource Center; Health Information Technology__Best Practices Transforming Quality, Safety, and Efficiency [Accessed 26 June 2013]. Available from: http://www.infobridge.org/asp/documents/3254.pdf.

10. Pourasghar F, Malekafzali H, Koch S, Fors U. Factors influencing the quality of medical documentation when a paper-based medical records system is replaced with an electronic medical records s. Int. J. Technol Assess Heal Care. 2008; 24(4):445-51.

11. Patient safety and the Electronic Health Record. Committee Opinion No 472. American College of Obstetrician and GynecologIist. Obs Gynecol. 2010;116:1245-7.

12. Kalogriopoulos NA, Baran J, Nimunkar AJ, Webster JG. Electronic Medical Record Systems for Developing Countries: Review. Engineering in Medicine and Biology Society, 2009. EMBC 2009. Annual International Conference of the IEEE. DOI: 10.1109/ IEMBS.2009.5333561.

13. Jack T, Bond G. A comparison of electronic records to paper records in mental health centers. Int. J. Qual Heal Care. 2008; 20(2):136-43.

14. Mckay MV, Douglas GP. Touchscreen Clinical Workstations at the Point of Care : Guiding Protocols and Managing Data in Malawi. Baobab Health Unpublished Observations. 2008; (2).

15. WHO. Lilongwe, Malawi - Middlesbrough, England. 2015. [Accessed: 30 August 2017] Available from: http://www.who.int/ patientsafety/implementation/apps/first_wave/malawi_middlesbrough/ en/

16. Ibrahim IYS. Queen Elizabeth Central Hospital as a Centre of Excellence in Service Provision, Teaching, and Research: Is Memorandum of Understanding the Solution? University of Malawi; 2006. [Accessed 30 August 2017]. Available from: http:// www.medicmalawi.org/wp-content/uploads/2012/03/TBrowningElective-2-1.pdf

17. Nour El Din MMM. Physicians' Use of and Attitudes Toward Electronic Medical Record System Implemented at a Teaching Hospital in Saudi Arabia. J Egypt Public Health Assoc. 2007;82(5).

18. Sánchez JL, Savin S, Vasileva V. Key Success Factors in Implementing Electronic Medical Records in University Hospital of Rennes. University Hospital of Rennes. L'Ecole Nationale de la Santé Publique (ENSP):2005 p. 1-59.

19. Al-azmi SF, Al-enezi N, Chowdhury I. Users' attitudes to an electronic medical record system and its correlates: a multivariate analysis. Heal Inf Manag J. 2009;38(2).

20. Brumini G, Koviæ I, Zombori D, Luliæ I, Petrovecki M. Nurses' attitudes towards computers_cross sectional questionnaire study. Croat Med J. 2005;46(1):101-4. 
21. Aqil A, Lippeveld T and Hozumi D. PRISM framwork: a paradigm for shift for strengthening and evaluating routine health information systems. Health and Policy Planning 2009; 24:217-228. doi:10.1093/ heapol/czp010.

22. Msukwa MKB. User Perceptions on Electronic Medical Record System (EMR) in Malawi [Internet]. University of Malawi; 2011 [Accessed 20 Sept 2013]. Available from: http://www.medcol.mw/ commhealth $/ \mathrm{mph} /$ dissertations/martin msukwa_Approved.pdf

23. Alharthi H, Youssef A, Radwan S, Al-muallim S, Zainab A. Physician satisfaction with electronic medical records in a major Saudi Government hospital. J Taibah Univ Med Sci [Internet]. Elsevier Ltd; 2014 [Acessed 10 April 2015];9(3):213-8. Available from: http:// dx.doi.org/10.1016/j.jtumed.2014.01.004

24. Ayatollahi H, Bath PA, Goodacre S. Factors influencing the use of IT in the emergency department: A qualitative study. Health Informatics J. 2010;16(3):189-200.

25. Lium JT. Use of Electronic Medical Records and the road towards paperless hospitals in Norway : A socio-technical perspective. Thesis. Norwegian University of Science and Technology, 2007. [Accessed 30 August 2017]; Available from: https://www.jhia-online.org/index.php/ jhia/article/view/124
26. Moody LE, Slocumb E, Berg B, Jackson D. Electronic health records documentation in nursing nurses' perceptions, attitudes, and preferences. Comput Inf Nurs. 2004;22(6):337-44.

27. Usage of Electronic Medical Records Among Healthcare Workers in Selected Health Facilities in Nairobi, Kenya Department of Sociology and Social Work; University of Naiorobi. 2013. [Accessed: 30 August 2017] Available from: http://chss.uonbi.ac.ke/printpdf/6187

28. Lærum H, Ellingsen G, Faxvaag A. Doctors' use of electronic medical records systems in hospitals_ cross sectional survey. BMJ 2001;3231344. 2001;323:1344.29.

29. Meinert DM, Peterson D. Perceived importance of EMR functions and physician characteristics_Journal of Systems and Information Technology_Vol 11, No 1.pp. 57-70. DOI:10.1108/13287260932412.

30. Giaedi T. The Impact of Electronic Medical records on improvement of health care delivery. Libyan J Med. 2008;3(1):4. 